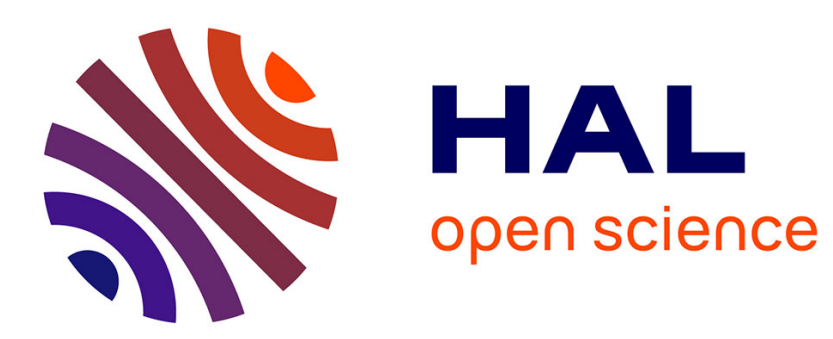

\title{
Seismicity rate before eruptions on Piton de la Fournaise volcano: Implications for eruption dynamics.
}

Marielle Collombet, Jean-Robert Grasso, V. Ferrazzini

\section{To cite this version:}

Marielle Collombet, Jean-Robert Grasso, V. Ferrazzini. Seismicity rate before eruptions on Piton de la Fournaise volcano: Implications for eruption dynamics.. Geophysical Research Letters, 2003, 30 (21) (21), pp.2099. 10.1029/2003GL017494,2003 . hal-00109912

\section{HAL Id: hal-00109912 https://hal.science/hal-00109912}

Submitted on 10 Feb 2021

HAL is a multi-disciplinary open access archive for the deposit and dissemination of scientific research documents, whether they are published or not. The documents may come from teaching and research institutions in France or abroad, or from public or private research centers.
L'archive ouverte pluridisciplinaire HAL, est destinée au dépôt et à la diffusion de documents scientifiques de niveau recherche, publiés ou non, émanant des établissements d'enseignement et de recherche français ou étrangers, des laboratoires publics ou privés. 


\title{
Seismicity rate before eruptions on Piton de la Fournaise volcano: Implications for eruption dynamics
}

\author{
Marielle Collombet \\ Laboratoire de Géophysique Interne et Tectonophysique, Observatoire de Grenoble, Université Joseph Fourier, Grenoble, \\ France \\ Jean-Robert Grasso \\ Laboratoire de Géophysique Interne et Tectonophysique, Observatoire de Grenoble, France and Institute of Geophysics and \\ Planetary Physics University of California, Los Angeles, California, USA

\section{Valérie Ferrazzini} \\ Observatoire Volcanologique du Piton de la Fournaise, Reunion Island, IPG Paris, France
}

Received 4 July 2003; revised 13 August 2003; accepted 17 September 2003; published 7 November 2003.

[1] Individual eruptions are difficult to foresee using daily seismicity at Piton de la Fournaise (PdlF) volcano, except within a few hours from the eruption time. However, when using a superposed epoch analysis for all of the 15 eruptions in the 1988-2001 period, we find that the seismicity rate increases 2 weeks before the eruption time as $\dot{N}(t) \sim\left(t_{e}-\right.$ $t)^{-a}, t_{e}$ being the eruption time. Such an increase mimics the pattern of stacked foreshock sequences, i.e., a power law increase in seismicity rate before earthquakes that is proposed to emerge from aftershocks properties [Helmstetter et al. 2003]. It argues for the bursts of seismicity rate before eruptions to both result from the volcano dynamics (volume or pressure increase induced by magma) and from the cascades of earthquake interactions. This latter process produces stochastic fluctuations in the seismicity rate that perturb any single pre-eruption time series. The PdlF seismicity highlights a brittle pre-eruption damage process which starts at least 2 weeks prior to eruption time. Because this increase is only measured upon averaging, it suggests that during the brittle damage phase the direct effect of volcano dynamics on the seismicity rate remains on the same order of magnitude as the seismicity rate triggered by volcano earthquake interactions. INDEX TERMS: 7209 Seismology: Earthquake dynamics and mechanics; 7280 Seismology: Volcano seismology (8419); 8414 Volcanology: Eruption mechanisms; 8419 Volcanology: Eruption monitoring (7280). Citation: Collombet, M., J.-R. Grasso, and V. Ferrazzini, Seismicity rate before eruptions on Piton de la Fournaise volcano: Implications for eruption dynamics, Geophys. Res. Lett., 30(21), 2099, doi:10.1029/2003GL017494, 2003.

\section{Introduction}

[2] A primary goal in monitoring active volcanoes is to capture from surface measurements the sub-surface movement of magma in order to both gain an understanding of how a volcano works and to detect precursors of impeding eruptions. Volcano seismicity is thought to reflect magma transfers through two distinct types of processes, namely those originating in the fluid and those originating in the rock matrix [e.g., Chouet, 1996]. We use the volcano seismicity, the so-called volcano tectonic (VT) events that are manifestation of shear failure within the volcano edifice, to analyse the pre-eruption behavior of the 15 eruptions on the PdIF volcano that occurred in the May 1988-July 2001 period. These events are genuine earthquakes that work as stress gauges within the rock matrices surrounding the magma conduits and reservoirs. Each of these earthquakes maps inelastic damage within the volcano edifice the same way acoustic emission allows one to follow the evolving damage process in a rock sample during loading at laboratory scales.

[3] Volcano seismicity is often the first sign of renewed volcanic activity. Precursory seismic activity from VT events, usually reported as seismic swarms, may last from days to months or even years [Benoit and McNutt, 1996; Chouet, 1996; and references therein]. Accordingly, eruption processes still evade thorough understanding and forecasts of the time to eruption are nor robust neither accurate. During the final approach to eruption volcanologists often measure (in forward analysis) an acceleration only a few hours to a few days before the eruptions. This acceleration in seismicity, which is not an ubiquitous phenomenon before explosive eruptions, is also reported in some retrospective case studies, as a power law accelerating seismicity during a few days up to 10 days before andesitic eruptions e.g., for a review and reference therein [Kilburn, 2003]). But before effusive eruptions on basaltic volcano this final approach is much shorter in time, ranging from tens of minutes to tens of hours and a power law acceleration of seismicity has never been reported [Klein, 1984; Tilling and Dvorak, 1993; Aki and Ferrazzini, 2000].

[4] Using two pre-eruption sequences, Voight [1988] proposes that the increase in the rate of volcano observables $\dot{N}$, as measured by the deformation rate or the seismicity energy rate before eruption of Mt St Helens and Bezymyanny volcano, respectively, scales with the acceleration $d \dot{N} / d t$ according to

$$
\frac{d \dot{N}}{d t}=A \dot{N}^{\alpha} .
$$

In (1) $A$ and $\alpha$ are empirical constants. For $\alpha>1$, this relationship predicts a divergence of the observed rate at 


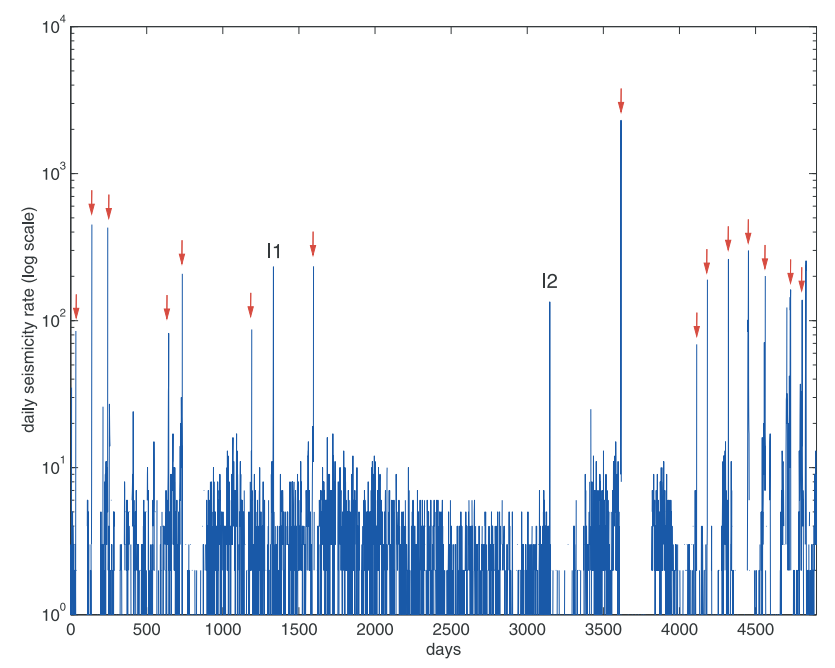

Figure 1. Daily seismicity rate on the Piton de la Fournaise volcano from 04/15/1988, (day 1) to 09/12/ 2001, day 4899. Arrows point out the 15 eruptions that occured in this period. Prominent bursts of seismicity that do not result in an eruption are labelled as intrusions (I1, I2).

some finite critical time $t_{e}$. By analogy between failure mechanics and eruption processes of volcanoes Voight [1988] suggested that the empirical law defined by (1) could apply for the behavior of the deformation or seismicity rate before an explosive eruption. Integrating (1) gives

$$
\dot{N} \sim\left(t_{e}-t\right)^{\frac{-1}{\alpha-1}}
$$

[5] Equation (2) may be seen as a special case of a general expression for time to failure laws that have recently been interpreted as resulting from cooperative critical phenomena see [Sammis and Sornette, 2002, for a review]. Fluctuations of the values of the $\alpha$ exponent that are reported to range between 1 and 2 before andesitic eruptions inhibit an accurate forecast of the time to eruption [Kilburn, 2003]. For $\alpha \neq 2$ the inverse rate as a function of time is no longer a straight line and the fitting process to determine the time to eruption is much more difficult [e.g., Voight, 1988]. In this paper, we analyse the pre-eruptive daily seismic event rate before 15 eruptions on PdlF volcano. We show how the seismicity rate acceleration, which is not recovered for each single eruption, can emerge as an average pattern when stacking all pre-eruption sequences. We discuss possible models that can be relevant to understanding the volcanic processes that lead to this average pre-eruption behavior.

\section{Seismicity Patterns on PdIF}

[6] The PdlF volcano is a shield volcano with an effusive erupting style, with low viscosity basaltic magma. In the May 1988-July 2001 period 15 eruptions were seismically monitored. The PdlF seismicity catalog consists of data from the 16 seismic stations network that is operated for volcano monitoring [Sapin et al., 1996; Aki and Ferrazzini, 2000]. In the 1988-2001 period the geometry and instru- mental characteristics of the seismic network remained stable on the volcano, with a magnitude detection threshold of 0.5 [Grasso and Bachelery, 1995]. Less than 10\% of the seismicity is located, most of the events only being recorded by the 3 summit stations located $1 \mathrm{~km}$ apart from each other. Because the PdlF volcano is a hot spot type, in an intraplate setting, there is little, if any, tectonic interaction with neighboring active structures. Contrary to the Mauna LoaKilauea volcanic system, there is no seismically active flank sliding or basal faulting of the PdlF. Accordingly, during the 1988-2001 period the PdlF seismicity is small with a maximum magnitude of 2.5 [Grasso and Bachelery, 1995; Aki and Ferrazini, 2001], and located within a radius of a few $\mathrm{km}$ beneath the central caldera. It ranges in depth from $2 \mathrm{~km}$ above sea level to $3 \mathrm{~km}$ below [e.g., Sapin et al., 1996]. Since the onset of the seismic monitoring of the volcano in 1981, this location pattern has remained stable over time [Delormes et al., 1989; Sapin et al., 1996; Aki and Ferrazzini, 2001]. This seismogenic volume is also thought to be the main path for the magma flow toward the surface [Bachelery, 1999]. There is no definitive answer on the PdlF magma storage system. A shallow system is suggested to exist between $1.5 \mathrm{~km}$ above sea level and $1 \mathrm{~km}$ depth [Lenat and Bachelery, 1990; Sapin et al., 1996; Aki and Ferrazini, 2000, 2001].

[7] No robust rule exists to forecast an eruption on this type of volcano [e.g., Klein, 1984; Sapin et al., 1996]. As for many volcano observatories, daily seismicity rates are indications of PdlF volcano activity, which is a robust database over all the 1988-2001 period (Figure 1). Over the 04/1988-09/2001 period and for all the 15 eruptions that occurred on PdlF, a large number of earthquakes occurred during each eruption day, $\dot{N}>60$, when compared to the 3-4 average background daily seismicity rate (Figure 1). For this period the $\dot{N}>60$ rate was also recovered for 2 seismic sequences in July 1991 and November 1996 that did not end up surface magma flow (Figure 1). Using the earthquake occurrence rate only, these seismic crises were post-labelled as intrusions by the OVPF observatory [e.g., Grasso and Bachelery, 1995; Sapin et al., 1996; Aki and Ferrazzini, 2000]. In the following we analyze intermediate term seismicity patterns, i.e., the pre-eruptive seismicity days to weeks before PdlF eruptions.

\subsection{Seismicity Patterns Prior to 15 PdIF Eruptions, 1988-2001}

[8] Because of the background seismicity level even during repose periods of the volcano (Figure 1), it is difficult to extract the earthquakes that are solely related to the pre-eruption process, days to weeks before the eruptions. To enhance the signal to noise ratio, we use a superposed epoch analysis, for the 15 eruptions of the 04/ 1988-09/2001 period. The resulting behavior shows the daily seismicity rate increasing above the noise level 2 weeks before the eruption (Figure 2). For the last 10-15 days this increase follows a power law distribution as $\dot{N}(t)$ $\sim\left(t_{e}-t\right)^{-a}, t_{e}$ being the eruption time (Figure 2). A rough exponent value, $0.7 \pm 0.2$ cannot be accurately constained due to the weak number of daily rates. The exponent value is determined by linear regression, the error bars are derived from the different exponent values that are obtained when, using 13, 15 and 20 days for the 


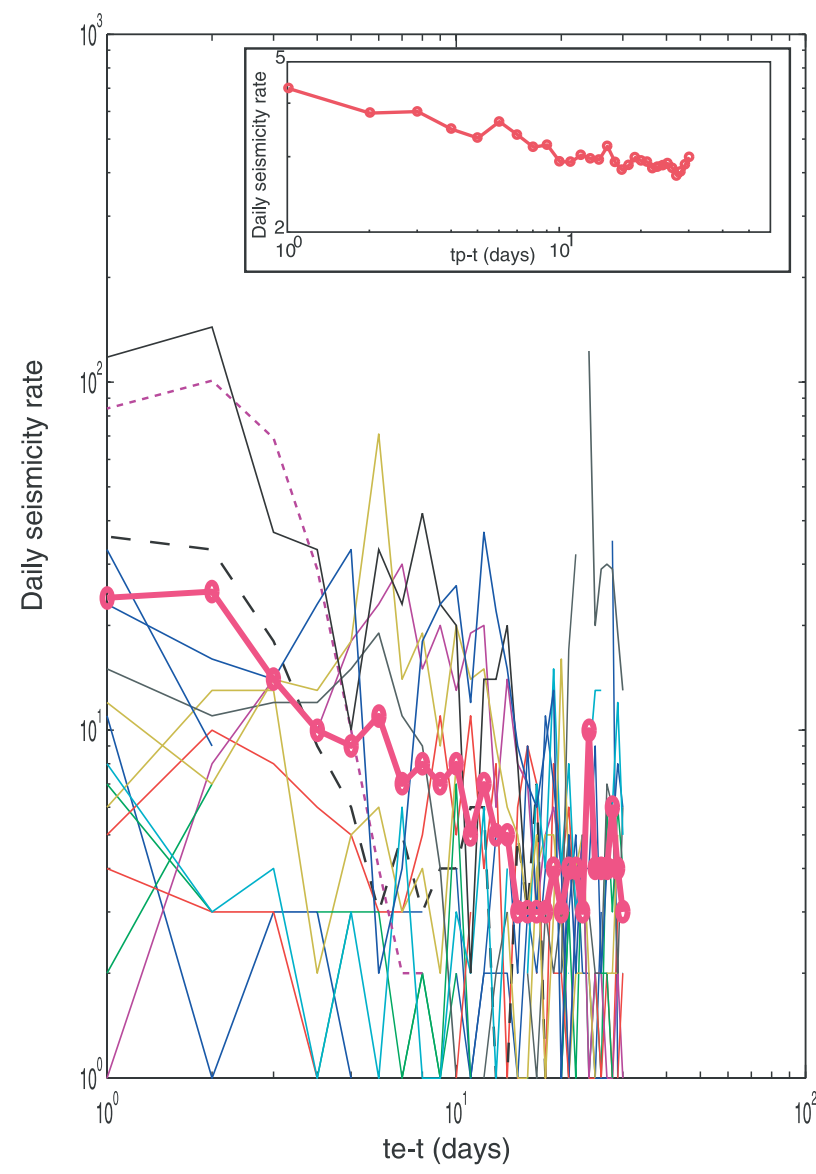

Figure 2. Daily seismicity rate during the 30 days before each of the 15 eruptions in the $04 / 15 / 1988$ to $09 / 12 / 2001$ period. The 30 day interval is the smallest time between two consecutive eruptions in this period. Each "day one" represents one day before eruptions. The thick curve, circles, is the mean stack over the 15 eruptions. Insert: Trend before peak values of 5-20 events/day); tp: time before the peak.

duration of the pre-eruption sequence. We checked that this distribution is not in fact driven by a single preeruption seismicity sequence, including the large seismicity rate preceding the 1998 eruption.

\subsection{Characterization of the Background Seismic Activity Outside the Eruption Period}

[9] In order to estimate a background seismic level we removed from the seismicity catalog all data 15 days before each eruption. In the catalog which consists of 4899 days, $50 \%$ of the seismicity occurs at distance of more than 15 days from any eruption. Within this background seismicity, there are also fluctuations in the seismicity rate (Figure 1). Using the superposed epoch analysis, for the 348 seismic sequences before days where seismicity rates range from 5-20 event/day, we recover a power law increase (Figure 2). This attests that endemic accelerations of seismicity exist within the PdlF background seismicity. Because Reunion Island is located in a low seismicity rate, intraplate setting, regional tectonics is thus probably not responsible for the remaining $50 \%$ of seismicity. This background seismicity level is likely to be a consequence of recurrent dynamics of fluid rock interactions within the shallow edifice [Grasso and Bachelery, 1995; Lahaie and Grasso, 1998]. These interactions involve endogeneous fluid transfers (magma or water), posteruption relaxation and temperature and pressure changes, including earthquake interactions. Because the seismicity of the eruption days amounts to $35 \%$ of the whole catalog, the average increase of the seismicity rate 15 days before the eruption corresponds to $15 \%$ of the PdlF seismicity over $5 \%$ of the time length. This accelerating seismicity cannot be isolated from the remaining $50 \%$ of the seismicity due the background seismicity (Figure 1).

\section{Pre-Eruption Processes as Mapped by Seismicity Patterns on PdIF Volcano}

[10] Analysis of the daily seismicity rates on PdlF allows us to identify and identify different steps in the eruption mechanics. First, the average increase of the seismicity rate implies that the PdlF eruptions emerge from a damage process that started at least 2 weeks before the day of eruption. For the few earthquakes that can be located, no migration was reported during these 2 week periods [e.g., Sapin et al., 1996]. This suggests the brittle damage process to be primarily localized in the wall of the magma storage system [e.g., Sapin et al., 1996]. Second, a power law acceleration is also recovered on average before the peaks of the seismicity rate that occurred in the background seismicity, 30 days apart from each eruption. This makes it difficult to isolate at $\mathrm{PdlF}$ volcano the pre-eruptive seismicity, i.e., $15 \%$ of the whole PdlF seismcity, from the background volcano seismicity, which is $50 \%$ of the whole seismcity. When focusing on the acceleration of the seismic rate 2 weeks before eruption time, 2 types of generic processes can be proposed. A critical point model for failure (for a review and references therein see Sammis and Sornette [2002]) and a cascade model for earthquake interactions (for a review and references therein, see Helmstetter et al. [2003]). In the next sections we discuss how these two models can reproduce the PdlF pre-eruptive pattern.

\subsection{PdIF Eruption and Failure Model}

[11] Earthquakes are symptoms of volcano processes that drive the eruption. These processes could correspond either to an injection of fluid from the mantle or to the dynamics of fluid transfers within the storage zone, i.e., lens interaction or crystallization [e.g., Chouet, 1996; McNutt, 1996]. In such a setting, the observed power law distribution of the PdlF seismicity rate toward the time of eruption mimics the pattern predicted by brittle damage before macroscopic failure. It was empirically proposed to apply for an explosive eruption style by Voight [1988]. This generic model is the critical point concept for macroscopic failure, where a power law increase of damage should re-currently occur before each macroscopic failure (for a review see [Sammis and Sornette, 2002]). In this model the accelerating seismicity rate is primarily driven by changes in the volcano dynamics that will lead to an eruption. In this case, the preeruptive increase in volume or pressure results either in damaging a storage structure or in activating a percolation 
path within the volcano edifice to allow magma to flow toward the surface. Experimental failure of reservoir tanks as monitored by acoustic emission is reported to have a power law increase of seismicity rate toward the time to failure [Anifrani et al., 1995]. This experiment and the associated failure model could be an analog of magma reservoir damage for the volcano mechanics. The key difference between this failure model for eruption dynamics and PdlF observations is that this model predicts recurrent power law increases of the seismicity rate for every single eruption. This is not observed on PdlF. Accordingly, while such a model could possibly reproduce pre-eruptive seismicity that is sometimes observed before explosive eruptions [e.g., Voight, 1988] it appears not to be appropriate to reproduce PdlF seismicity patterns before effusive eruption.

\subsection{Interplay Between PdIF Seismicity and PdIF Volcano Dynamics}

[12] The statistical emergence of an acceleration of the seismicity rate toward the day of eruption on PdlF volcano is reminiscent of the foreshock patterns before mainshocks [Kagan and Knopoff, 1978; Jones and Molnar, 1979]. That is, there are few foreshocks if any for a single earthquake, but when stacking many mainshocks, a robust law emerges. It has been recently demonstrated that this law can result from earthquake interactions through cascades of aftershocks [Helmstetter et al., 2003]. This model just requires a background seismicity level and the Gutenberg-Richter and Omori laws for seismicity. All of these patterns are reported for volcano seismicity [Klein, 1984; Grasso and Bachelery, 1995; Sapin et al., 1996; Dieterich et al., 2000]. With such basic ingredients Helmstetter et al., [2003] have demonstrated that bursts of accelerating seismicity exist as the consequence of cascades in triggering and triggered events. Accordingly on the PdlF volcano, this model suggests that the accelerating seismicity does not require a major change in the dynamics of the volcano system, with part of this acceleration possibly emerging from the earthquake interactions. Numerical simulations by Lahaie and Grasso [1998] show that endogeneous fluid transfers in a network of storage lenses trigger seismicity that reproduces the background PdlF seismicity. We suggest that this direct volcano seismicity is further enhanced and accelerated by a feedback mechanism due to earthquake interactions through aftershocks. This statistical complexity for each path toward eruption emerges from the two types of control parameters for the volcano seismicity: the volcano dynamics and the earthquake interactions. Such an average path toward eruption that emerges from stacking 15 PdlF pre-eruptive sequences was first proposed by Collombet et al. [2002]. The same pattern has since been reported by Chastin and Main [2003] when stacking the 35 eruptions of Kilauea, Hawaii, volcano, for the 1959-1983 period. This argues for this pattern to possibly be the rule for low viscosity, effusive eruptions. Because this pre-eruptive seismicity pattern is only recovered on average, it inhibits a deterministic eruption forecast when using solely seismicity rate data.

\section{Conclusion}

[13] A power law accelerating seismicity rate is observed 2 weeks before the eruption time when a superposed epoch analysis are used on PdlF volcano. This argues for the PdlF eruptions to emerge, on average, from a damage process that starts at least 2 weeks before the eruption day. The accelerating pattern is also recovered by stacking seismicity before the peaks of the background seismicity. We propose that the average acceleration of the PdlF volcano seismicity rate before eruptions, the complexity of each single pre-eruptive seismicity sequence, and the accelerations within the background seismicity result from two interacting processes: the fluid rock interactions that are driven by volcano dynamics and the earthquake interactions that are driven by the generic statistical laws of earthquakes. The accelerating pattern that emerges from $15 \mathrm{PdlF}$ pre-eruptive sequences appear to be a generic behavior for low viscosity, effusive eruptions.

[14] Acknowledgments. We thank OVPF staff in charge of the seismic network since 1980, A. Helmstetter, P. Bachelery, A. Hirn, J. Battaglia, T. Staudacher M. Werner and S. Persch for stimulating discussion and comments. Reviews by anonymous referees were helpfull to clarify the paper. MC is supported by EC grant EVG-CT-2001-00040, Volcalert project.

\section{References}

Aki, K., and V. Ferrazzini, Seismic monitoring and modeling if an active volcano for prediction, J. Geophys. Res., 105, 16,617-16,640, 2000.

Aki, K., and V. Ferrazzini, Comparison of Mount Etna, Kilauea, and Piton de la Fournaise by a quantitative modeling of their eruption histories, J. Geophys. Res., 106, 4091-4102, 2001.

Anifrani, J. C., C. Le Floc'h, D. Sornette, and B. Souillard, Universal logperiodic correction to renormalization group scaling for rupture stress prediction from acoustic emissions, J. Phys. I. Fr. 5, 631-638, 1995.

Bachelery, P., Le Fonctionnement des volcans boucliers, memoire HDR, Univ. e de la Reunion, St Denis, France, pp. 698, 1999.

Benoit, J. P., and S. McNutt, Global Volcanic Earthquake Swarm data base 1979-1989, USGS open-file report 96-99, USGS, Reston, Va, pp. 333, 1996.

Chastin, S., and I. Main, Statistical analysis of daily seismic event rate as a precursor to volcanic eruptions, Geophys. Res. Lett, in press, 2003.

Chouet, B., Long period volcano seismicity: Its source and use in eruption forecasting, Nature, 16,617-16,640, 1996.

Collombet, M., J. R. Grasso, and V. Ferrazzini, Seismicity rate and volcano dynamics at Piton de la Fournaise Volcano, (Iandian Ocean), Eos Trans. $A G U, 83(47)$, Fall Meet. Suppl., Abstract V21A-1171, 2002.

Delormes, H., P. Bachelery, A. Blum, J. L. Cheminee, J. F. Delarue, J. C. Delmond, A. Hirn, J. C. Lepine, P. Vincent, and J. Zlotnicki, March 1986 eruptive episodes at Piton de la Fournaise volcano (Reunion, Island), J. Vol. Geoth. Res., 36, 199-209, 1989.

Dieterich, J., V. Cayol, and P. Okubo, The use of eathquake rate changes as a stress meter at Kilauea volcano, Nature, 408, 457-460, 2000.

Grasso, J.-R., and P. Bachelery, Self-Organized volcanic earthquakes as a diagnostic approach to volcano mechanics: Validation on Piton de la Fournaise, Geophys. Res. Lett., 22, 2897-2900, 1995.

Helmstetter, A., D. Sornette, and J.-R. Grasso, Mainshocks are aftershocks of conditional foreshocks: How do foreshock statistical properties emerge from aftershock laws, J. Geophys. Res., 108(B1), 2046, doi:10.1029/ 2002JB001991, 2003

Jones, L., and P. Molnar, Some characteristics of foreshocks and their possible relationship to earthquake prediction and premonitory slip on fault, J. Geophys. Res., 84, 356-3608, 1979.

Kagan, I., and L. Knopoff, Statistical study of the occurrence of shallow earthquakes, Geophys. J. R. Astr. Soc., 55, 67-86, 1978.

Kilburn, Hierarchical fracturing as a key to forecasting volcanic eruptions, J. Vol. Geoth. Res., 2623, 1-19, 2003.

Klein, F., Eruptive forecasting at Kilauea volcano Hawaii, J. Geophys. Res., 89, 3059-3073, 1984.

Lahaie, F., and J.-R. Grasso, A fluid-rock interaction cellular automaton of volcano mechanics: Application to the Piton de la Fournaise, J. Geophys. Res., 103, 8649-9637, 1998.

Lenat, J.-F., and P. Bachelery, Structure and dynamics of the central zone of Piton de la Fournaise volcano, in Le volcanisme de la Reunion, edited by Lenat, CRV, OPG Clermont, France, 257-296, 1990. 
McNutt, S., Seismic monitoring and eruption forecasting of volcanoes: A review of the state of the art and case histories, in Monitoring and mitigation of volcano hazards, edited by Scarpa and Tiling, Springer, Berlin, 99-146, 1996.

Tilling, R., and J. Dvorack, Anatony of a basaltic volcano, Nature, 363, $125-133,1993$.

Sapin, M., A. Hirn, J. C. Lepine, and A. Nercessian, Stress, failure and fluid flow deduced from earthquakes accompanying eruptions at Piton de la Fournaise Volcano, J. Vol. Geoth. Res., 70, 145-167, 1996.

Sammis, C. G., and D. Sornette, Positive feeback, memory, and the predictability of earthquakes, Proc. Nat. Ac. Sci, 99, 2501-2508, 2002.
Voight, B., A method for prediction of volcanic eruption, Nature, 332, $125-130,1988$

M. Collombet, LGIT, Observatoire de Grenoble, BP 53X, 38041 Grenoble Cedex, France. (Marielle.Collombet@obs.ujf-grenoble.fr)

V. Ferrazzini, OVPF, La plaine des Cafres, 14 route nationale 3, 97418, Reunion, France. (ferraz@ipgp.jussieu.fr)

J.-R. Grasso, LGIT, Observatoire de Grenoble, BP 53X, 38041 Grenoble Cedex, France. (Jean-Robert.Grasso@obs.ujf-grenoble.fr) 